\title{
Cost of Cancer and Coping up Mechanism among Indian Status
}

\section{A. Sangamithra}

Professor, Department of Economics, Bharathiar University, Coimbatore, Tamil Nadu, India

(D) https://orcid.org/0000-0003-4761-8150

\section{S. Vishnu}

Ph.D. Research Scholar, Department of Economics

Bharathiar University, Coimbatore, Tamil Nadu, India

Volume: 9

Issue: 3

Month: June

Year: 2021

P-ISSN: 2319-961X

E-ISSN: 2582-0192

Received: 23.02.2021

Accepted: 15.04.2021

Published: 01.06.2021

Citation:

Sangamithra, A., and S. Vishnu. "Cost of Cancer and Coping up Mechanism among Indian Status." Shanlax International Journal of Economics, vol. 9, no. 3, 2021, pp. 5-9.

DOI: https://doi.org/10.34293/ economics.v9i3.3751

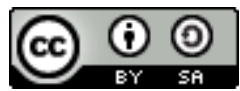

This work is licensed under a Creative Commons Attribution-ShareAlike 4.0 International License

\section{Abstract}

This study exclusively focuses on accessing the level of perceived economic support and quality of life of cancer patients' cost of cancer with coping up and drawing suggestions to achieve a high level of quality of life and addressing the issues of the day-to-day life problems. This study may help to understand the prevailing status of the person with cancer and help to find the level of perceived social support among the cancer patients. The study discovers the level of quality of life of the persons affected by cancer.

Keywords: Cancer, Disease in India, Economic burden, Economic cost, Treatment cost

\section{Introduction}

Health is an essential determinant of Economic and Social development. Cancer is a collection of similar disorders in which body cells divide without stopping and spread into surrounding tissues. A healthy population is defined as one that safeguards health of its members and a resource for the well-being of its members. The Government has realized that diseases affect human progress and ultimately, the nation and all over the world make efforts to counter conditions and preserve and protect the human race from all possible hazards of health. Cancer is the most common cause of sickness and death rate in the world today after cardiovascular disease. Sixty lakh people die due to cancer every year. It is estimated that last year there will be fifteen million new cases every year. Cancer is one of the most severe diseases that can affect a person. With over 200 different types of cancer that can occur within the human body, there are numerous treatments prepared for cancer patients, depending largely on the location, scope, and severity of cancer, as well as on the overall health of the patient. (WHO Cancer Report, 2020). To attain the highest possible standard of health, good health is the basic foundation for the promotion of creativeness, self-discipline, self-confidence, and dynamism in people, which are necessary to increase the nation's productive capacity.

\section{Cancer: A Serious Disease}

Cancer is universal; the only variation occurs in types, sites, or other clinic epidemiologic parameters. Cancer is the most common cause of morbidity and mortality in the world today after cardiovascular problems. It is estimated that by last year there will be 1.5 billion new cases every year. Cancer is one of the most serious diseases that can affect a person. There are numerous treatments available for cancer patients, depending largely on the location, scope, and severity of cancer, as well as on the overall health of the patient. 
Cancer is a group of diseases with related symptoms, which can occur in all living cells in the body, and several cancer types have different natural histories. The myth that cancer affects people frequently in the developed country is being broken down by the fact that, of the 10 million new cancer cases seen each year worldwide, nearly 55 lakes are in the less developed countries. Cancer is the second most common cause of death in the developed world and a similar trend has emerged in developing countries. Cancer predominance in India is estimated to be around 2.5 million, with over $8,00,000$ new cases and 5,50,000 deaths happening each year due to this disease (Dinshaw, KA., et al., 1999). More than 70percent of the cases report for diagnostic and treatment services in the advanced stages of the disease, which has led to poor survival and a high mortality rate. (Ranjani Mohan, 2010).

According to epidemiological studies, 80-90percent of all cancers are due to environmental factors of which, lifestyle-related factors are the most significant and preventable. The significant risk representatives for cancer are tobacco, alcohol consumption, infections, dietary habits, and behavioral factors. Tobacco consumption, either by way of chewing or smoking, accounts for 50 percent of all cancers in men. Nutritional practices, reproductive and sexual practices account for 20-30 percent of cancers. Studies have shown that appropriate lifestyle changes will reduce the mortality and morbidity caused to cancer. This offers the prospect for initiating primary and secondary prevention measures for the control and prevention of cancers.

\section{Incidence of Cancer in India}

In India, cancer is a foremost cause of death with about 1.5 to 2 million cases at any time to which 7 lakhs new cases are added every year with 3 lakhs deaths. Over 1.5 million patients need facilities for diagnosis and treatment. Studies by WHO show that by 2026 with the awaited increase in life anticipation, the cancer strain in India will increase to about 14 lakh cases. (R. Srinivasan, 2010). The majority of Indian cancer sicker have late-stage not curable diseases ( 75 percent to 80 percent) when the first stage is diagnosed. The previous presentation could considerably enhance continued existence rates, making the recognition of factors hindering this vital. It is estimated that approximately 50 percent of cancer patients in developed countries die from their malignancy, whereas 80 percent of cancer patients die in developing countries. Presently in India, out of a million newly diagnosed cancer patients each year, more than 50 percent die within 12 months of diagnosis. Another one million cancer descendants show progressive disease within five years of diagnosis. Out of the 15 lakhs in need of palliative care, less than 1 lakh patients can be covered by the existing facilities. In 2005, due to cancer death, approximately 826,000 people in India; 519,000 under 70. This is forecast to rise disproportionally linked with cardiovascular and infectious diseases by 2030 to nearly 15 lakhs annually. Public health advocacy has been largely concentrated on infectious diseases, nutritional deficiencies, population stabilization, and recently on HIV/AIDS. Cancer has thus far been a comparatively less priority. (Alex Broom et al., 2009).

Table 1: Number of New Cases in 2020, Both Sexes, All Ages, in India

\begin{tabular}{|l|c|c|}
\hline \multicolumn{1}{|c|}{ Cancer } & Number & $\mathbf{\%}$ \\
\hline Breast & 178361 & 13.5 \\
\hline Lip, Oral Cavity & 135929 & 10.3 \\
\hline Cervix Uteri & 123907 & 9.4 \\
\hline Lung & 72510 & 5.5 \\
\hline Colorectal & 65358 & 4.9 \\
\hline Other Cancers & 748348 & 56.5 \\
\hline \multicolumn{1}{|c|}{ Total } & $\mathbf{1 3 2 4 4 1 3}$ & $\mathbf{1 0 0}$ \\
\hline
\end{tabular}

Source: World Health Organization / International

Agency for Research on Cancer / India-Globocan 2020

According to the World Health Organization and Globocan 2020 report states that India's population 1380004378 number at a glance. And the total number of new cases of cancer reported in 1324413 cases recorded - cancer death at 851678 number in the year 2020 all over India. And prevalent cases at last five years 2720251 reported. Mostly suffer 13.5 percent (178361) due to breast cancer and secondlargest at Lip, Oral Cavity at 10.3 percent (135929). Then after following cancer cases are cervix uteri (9.4 percent), lung (5.5 percent), colorectum (4.9 percent) and other cancers ( 56.5 percent). 


\section{Economic Burden of Cancer}

In overview, the incidence of cancers has been rising in most localities globally, but there is a significant difference between rich and developing countries. Incidence probabilities remain greatest in more developed regions, but mortality is much higher in developing countries due to an absence of before detected and access to medication facilities. And given that in developed nations, the number of cancer survivors heightened due to access to medication capabilities, so is required to increase direct medical expenditures in this region. The extent in developing countries' morbidity and mortality expenditures are outstanding.

\section{Cancer Economic Costs}

Direct cost: It encompasses all types of resource use, including the consumption of the professional family, volunteer, or patients' time and money. It also includes resources exhausted as downward outcomes of an intervention. For example, the cost of a screening invasion comprises not only the cost of the test itself but also the cost of additional tests, followup services for both actual and false-positive results, and the "downward" fees from hospitalization and healing '. Direct prices also include patients' out-ofpocket costs. Patients usually make co-payments for some co-operations not satisfied by their insurance, employer, or the government, such as the cost for over-the-counter medicines and individual plans. Direct non-healthcare charges accrue as well, which includes transport, lodging, and food.

Indirect Cost or Over Head Cost: These costs split the property that they are hard to allocate on a per-patient basis as these involve the cost of the support common across patients of many types such as clerical salaries, hygiene, and light in hospitals, libraries, etc. This cost component is often handled in an aggregate ad hoc fashion, but some analyzers use more systematic accounting organizations. Indirect Costs of Cancer Much less has been done to date to consider the secondary costs of cancer. Some preliminary work has been done, using agreement samples, to develop proper data instruments and data gathering strategies to measure the economic burden of cancer on the family and the employment experience of cancer survivors. The issue of cancer survivorship is currently considered a high-priority research area by the NCI.

\section{Cancer Treatment Costs}

Productivity Cost: Due to sudden sickness and death rate, cancer can lead to high productivityrelated costs for the patient, employer, and society. For the patient, it involves a substantial loss of earnings, as well as a reduction in length and quality of productive life. From the worker's perspective, these are viewed as "friction costs" associated with the inefficiencies of provisional replacement workers or costs related to recruiting and training a permanent replacement for a worker lost to illness.

Surgery Cost: Surgery can remove tumors, diagnose cancer, and determine how far cancer has spread. Several cancers sicker have surgery at least once as part of their diagnosis. Surgery can involve multiple medical providers, hospitals or focused facilities, and other essential components that result in various charges to patients and health insurers. Patients may be imposed additional facilities and other fees connected with where the surgery is performed.

Radiation Cost: Radiation therapy uses waves of high-energy particles to destroy or damage cancer cells. The patients gain radiation treatments at a hospital or cancer treatment equipment. Radiation treatment needs complex equipment and a team of health care providers. Treatment protocols vary, but some people living with cancer receive radiation daily or several times a week for many weeks, contributing to approximately high patient costs. Patients who have not yet met their out-of-pocket summit will likely be required to pay co-pays per visit or co-insurance based on the total cost of treatment. Noted transmission is generally admitted under a plan's medical benefit (or under Medicare Part B).

Pharmacological Therapy Cost: Medication is a trendy part of cancer treatment. This can include chemotherapy, targeted therapy, immunotherapy, hormone therapy, and supportive care like pain or anti-nausea medication. Some of these drugs can be taken as pills purchased through mail-order or at a pharmacy, and some are administered in a doctor's office, clinic, or hospital. The patient pays for a drug 
is often determined by the formulary tier on which the drug is placed. These tiers are groupings of drugs like "preferred," "non-preferred," and "specialty," for which the same copay or coinsurance applies. Covered pharmacological therapy is generally included in insurance policies as a separate pharmacy benefit.

\section{Conclusion}

The present study investigates the economic consequence of coping up mechanism and quality of life among cancer patients. The view of the analysis of various reviews and their results leads to the conclusion of the present research. The person affected with cancer experienced multiple feelings of fear about their economic management of a family, about their quality of life with better social support and peer group support. From the analysis of reviews, it is observed that a female respondent affected by cancer reported gender inequality promotes loss of social support and quality of life. The patient's income with cancer determines the influence on family support, social participation, social support, and quality of life. An increase in family support and social participation may enhance good quality of life. It might improve the psychosocial well-being and minimize or eliminate internalized stigma among the person with cancer. Economic burden, or cost-ofillness, research provides insight into the economic impact that sickness has on society and the economy and individuals and families.

\section{References}

Abdul-Khalek , Rima A., et al. "The Economic Burden of Cancer Care for Syrian Refugees: A Population-based Modeling Study." The Lancet, vol. 21, no. 5, 2020, pp. 637-644.

Ashtari, Sara, and Mohsen Vahedi. "Economic Burden of Gastrointestinal Cancer: Estimation and Importance." Translational Gastrointestinal Cancer, vol. 3, no. 4, 2014, pp. 178-181.

Benson, Ruth Boatemaa, et al. "Challenges, Coping Strategies, and Social Support among Breast Cancer Patients in Ghana." Journal of Advances in Public Health, 2020.
Brown, Martin L., et al. "The Burden of Illness of Cancer: Economic Cost and Quality of Life." Annual Review of Public Health, vol. 22, 2001, pp. 91-113.

Carrera, Pricivel M., et al. "The Financial Burden and Distress of Patients with Cancer: Understanding and Stepping-Up Action on the Financial Toxicity of Cancer Treatment." CA: A Cancer Journal for Clinicians, vol. 68, no. 2, 2018, pp. 153-165.

Guan Ng, Chong, et al. "Anxiety, Depression, Perceived Social Support and Quality of Life in Malaysian Breast Cancer Patients: A 1-Year Prospective Study." Health and Quality of Life Outcome, vol. 13, 2015.

Hamilton, Jill B., et al. "Perceptions of Support among Older African American Cancer Survivors." Oncology Nursing Forum, vol. 37, no. 4, 2010, pp. 484-493.

Hao, Shuang, et al. "The Economic Burden of Prostate Cancer - A Swedish Prevalencebased Register Study." BMC Health Services Research, vol. 20, 2020.

Hassen, Anissa Mohammed, et al. "Quality of Life and Associated Factors among Patients with Breast Cancer under Chemotherapy at Tikur Anbesssa Specialized Hospital, Addis Ababa, Ethiopia." PLoS One, vol. 14, 2019.

Heydarnejad, MS., et al. "Factors Affecting Quality of Life in Cancer Patients Undergoing Chemotherapy." African Health Sciences, vol. 11, no. 2, 2011, pp. 266-270.

Jeong, Ansuk, and Ji Yeong An. "The Moderating Role of Social Support on Depression and Anxiety for Gastric Cancer Patients and their Family Caregivers." PloS One, vol. 12, 2017.

Luszczynska, Aleksandra, et al. "Social Support and Quality of Life among Lung Cancer Patients: A Systematic Review." Psycho-oncology, vol. 22, 2013, pp. 2160-2168.

Mardanian-Dehkordi, Leila, and Leila Sadat Kahangi. "The Relationship between Perception of Social Support and Fatigue in Patients with Cancer." Iranian Journal of Nursing and Midwifery Research, vol. 23, no. 4, 2018, pp. 261-266. 
Melissant, Heleen C., et al. "Body Changes After Cancer: A Female Cancer Patient's Perceived Social Support and their Perspective on Care.” Supportive Care in Cancer, vol. 27, 2019.

Naseri, Nayyereh, and Fariba Taleghani. "Social Support in Cancer Patients Referring to Sayed Al-Shohada Hospital." Iranian Journal of Nursing and Midwifery Research, vol. 17, 2012, pp. 279-283.

Nayak, Malathi G., et al. "Quality of Life among Cancer Patients." Indian Journal of Palliative Care, vol. 23, no. 4, 2017, pp. 445-450.

Nguyen, Thi Xuan Trinh, et al. "The Economic Burden of Cancers Attributable to Infection in the Republic of Korea: A PrevalenceBased Study." International Journal of Environmental Research and Public Health, vol. 17, 2020.

Oh, Gyu Han, et al. "The Effect of Perceived Social Support on Chemotherapy-Related Symptoms in Patients with Breast Cancer: A Prospective Observational Study." Journal of Psychosomatic Research, vol. 130, 2020.

Sharma, K., et al. "Economic Cost Analysis in Cancer Management and its Relevance
Today." Indian Journal of Cancer, vol. 46, no. 3, 2009, pp. 184-189.

Sharma, Neelam, and Abhishek Purkayastha. "Factors Affecting Quality of Life in Breast Cancer Patients: A Descriptive and Cross-sectional Study with a Review of the Literature." Journal of Mid-Life Health, vol. 8, 2017, pp. 75-83.

Singh, Harinder, et al. "Quality of Life in Cancer Patients Undergoing Chemotherapy in a Tertiary Care Center in Malwa Region of Punjab." Indian Journal of Palliative Care, vol. 20, 2014, pp. 116-122.

Taylor, Shelley, et al. "Social Support, Support Groups, and the Cancer Patient." Journal of Consulting and Clinical Psychology, vol. 54, 1986, pp. 608-615.

World Health Organization Cancer Report 2020 at a Glance and Globocan India 2020.

Zaidi, Adnan A., et al. "The Financial Burden of Cancer: Estimates from Patients Undergoing Cancer Care in a Tertiary Care Hospital." International Journal for Equity in Health, vol. 11, 2012.

\section{Author Details}

Dr. A Sangamithra, Professor, Department of Economics, Bharathiar University, Coimbatore, Tamil Nadu, India,

Email ID: a.sangamithra@gmail.com.

S. Vishnu, Ph.D. Research Scholar, Department of Economics, Bharathiar University, Coimbatore, Tamil Nadu, India,

Email ID: vsssss572@gmail.com. 